\title{
Defining Substance Use, Misuse, and Abuse Examining the Continuum
}

This chapter focuses on defining substance use, misuse, and abuse-examining the continuum of substance use and society's response. It explores the impact that genes, prenatal exposure, and environment play in this disorder and how the nurses and physician assistants (PAs) can create safe spaces for these patients in a legal and ethical manner.

In this chapter, you will learn:

- What is meant by substance use disorder (SUD)

- The impact of genetics, epigenetics, and experience

- What statistics can tell us about SUDs in the U.S. population

- How to establish a safe environment for the SUD patient, whether or not in recovery

- Legal and ethical considerations

\section{WHAT IS MEANT BY SUD?}

The definition of SUD has changed over time, just as the words we choose to identify a person with an SUD have changed. So many of the words we are historically accustomed to using when discussing 
this disease, and the people who are diagnosed with it, are heavily burdened with judgment, prejudice, and stigma. It is not unusual to find people, even well-educated healthcare providers, who still think that SUD is not a real disease but rather a weakness of personality or a choice. This paradigm shift began with the discovery of new knowledge through research and the decision of the American Psychiatric Association (APA) to alter the model of substance use from addictive behaviors to a disease of substance use. This new framework reflects the repetitive disease pattern of SUD through multiple substances, from tobacco to opioids. The International Statistical Classification of Diseases and Related Health Problems, Tenth Revision (ICD-10), a coding system developed in the late 1980s by the World Health Organization (WHO), has multiple codes for the various SUDs and a methodology for identifying the substance involved as well as the degree of the problem.

We have made a decision, as collaborating authors, that words matter in the understanding of a disease, especially one that carries so much stigma. To this end, this book refrains from using the old, emotionally charged labels of "addict" and "junkie" and refers to these patients as persons with an SUD. As professional healthcare providers, this is a first step away from labels that blame to accepting these patients, as we do all others, as persons living and often suffering with a chronic disease.

Substance Abuse and Mental Health Services Administration (SAMHSA, 2015), referring to the Diagnostic and Statistical Manual of Mental Disorders, Fifth Edition (DSM-5; APA, 2013), explains that SUD is the term to be used, and degree of the disorder, from mild to severe, will be identified by the number of criteria met by the individual. Similar to other mental health disorders identified by the ICD10 and the DSM-5, SUDs are diagnosed when there is a clinical and functional impact on the individual's health, behaviors, and activities of daily living, including but not limited to social, academic, and employment issues.

What is the definition of SUD that we will be using in this book? An SUD is when the use of a substance (or substances) results in a clinically significant level of distress (National Alliance of Mental Illness [NAMI], n.d.). The level of stress that arises from the problematic substance use is a critical element. The two philosophical frameworks that will be utilized in defining SUD in this book are Bronfenbrenner and Morris's (2006) bioecological model of human development (BMHD) and the two-factor avoidance theory by Mowrer $(1947,1951,1956)$. These two frameworks reflect that behaviors are continuously evolving as determined by the experiences of individuals in specific contexts. The BMHD keeps its lens on the impact of the environment on the individual, whereas the 
Table 1.1

Biological Model of Human Development

\begin{tabular}{lll} 
System & Areas of Importance & Population Focus \\
\hline Chronosystem & $\begin{array}{l}\text { Sociohistorical conditions and } \\
\text { time events }\end{array}$ & Changes over time \\
Macrosystem & $\begin{array}{l}\text { Attitudes and ideologies } \\
\text { of the culture: economics, } \\
\text { socio-economics, legal, cultural, } \\
\text { and historical }\end{array}$ & $\begin{array}{l}\text { Social conditions, } \\
\text { economic conditions, } \\
\text { laws, and culture and } \\
\text { history }\end{array}$ \\
Exosystem & $\begin{array}{l}\text { Indirect personal environment: } \\
\text { local politics, social services, } \\
\text { industry, and employment }\end{array}$ & $\begin{array}{l}\text { Neighborhood, media, } \\
\text { extended family, and work } \\
\text { environment }\end{array}$ \\
& $\begin{array}{l}\text { Everyday connections: } \\
\text { interactions between } \\
\text { microsystems }\end{array}$ & $\begin{array}{l}\text { Family, siblings, peers, } \\
\text { school, work, and } \\
\text { religious affiliation } \\
\text { (church, temple, mosque, } \\
\text { etc.) }\end{array}$ \\
& & $\begin{array}{l}\text { Family, siblings, peers, } \\
\text { school, and work }\end{array}$ \\
Microsystem & $\begin{array}{l}\text { Immediate environment: } \\
\text { specific everyday contact } \\
\text { environments }\end{array}$ & Sex, age, health, etc.
\end{tabular}

Source: Adapted from Bronfenbrenner, U., \& Morris, P. A. (2006). The bioecological model of human development. In R. M. Lerner (Ed.), Handbook of child psychology, sixth edition-Volume 1: Theoretical models of human development (pp. 793-828). Hoboken, NJ: Wiley.

two-factor avoidance theory focuses on the individual. The combination of these frameworks provides an understanding of the complexity of this issue and can aid in the removal of blame and stigma from the diagnosis through understanding of the disease (Table 1.1 and Figure 1.1).

\section{Defining Use, Misuse, and Abuse}

According to the Centers for Disease Control and Prevention/National Center for Health Statistics (CDC/NCHS, 2017), over 100 Americans die from an opioid overdose every single day. The United States now finds itself in the midst of an opioid crisis that began in the 1990s when pharmaceutical companies promoted opioid pain relievers, assuring prescribers that these drugs were safe and would not result in misuse, abuse, or dependency. This was a myth, which has now been exposed by the fact that about $80 \%$ of those using heroin initially misused prescription opioids (Muhuri, Gfroerer, \& Davies, 2013). 


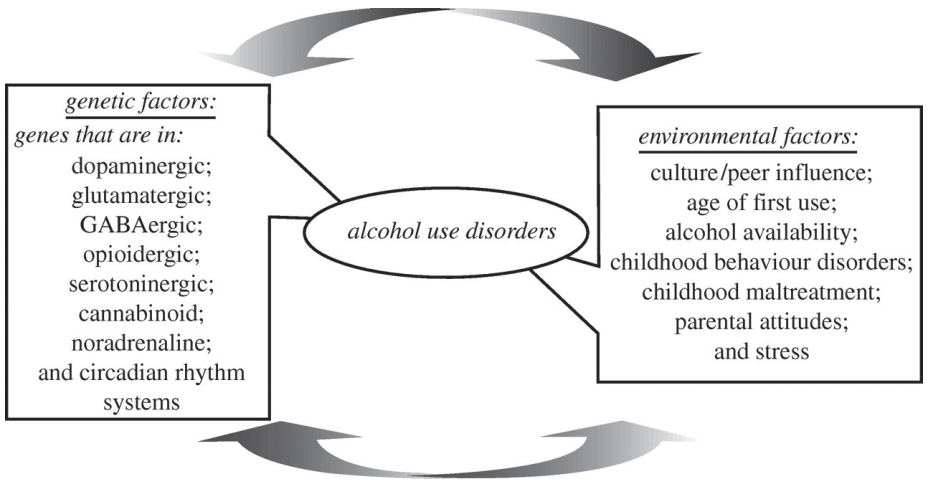

Figure 1.1 Two factor avoidance theory.

Source: Mowrer, O. H. (1956). Two-factor learning theory reconsidered, with special reference to secondary reinforcement and the concept of habit. Psychological Review, $63,114-128$.

Table 1.2

\section{Use, Misuse, and Abuse}

Use

Taking a substance for an intended purpose. This could be with medical direction or to get high. Any use of a substance is considered substance use. It can be legal, medicinal, recreational, or illegal use of a substance.

Misuse The use of a substance for an inappropriate or nonintended reason.

Abuse When a substance is intentionally or excessively used and results in harm to the user's mental or physical health.

In 2015, SUDs related to prescription pain killers affected about 2 million Americans, with over 33,000 dying from an overdose of prescription opioids, heroin, and fentanyl. Opioid-related SUD is an American public health crisis that affects the lives and health of newborns to seniors. Use of these opioids has led to misuse and abuse and, ultimately for some, death. The statistics reflect that prescription opioids for chronic pain sufferers are misused by $21 \%$ to $29 \%$ (Vowles et al., 2015). Of those individuals misusing their prescription opioids, about $8 \%$ to $12 \%$ will go on to present with an SUD, and of those, $4 \%$ to $6 \%$ will convert to using heroin (Carlson, Nahhas, Martins, \& Daniulaityte, 2016). The difference among use, misuse, and abuse reflects the critical downward cascade that leads to SUD (Table 1.2). 


\section{THE IMPACT OF GENETICS, EPIGENETICS, AND EXPERIENCE}

\section{Genetics}

Genetics is the science that investigates and reveals the passage of traits from one living organism to another. Our genes identify how we can inherit specific characteristics from our parents, which can include height, eye color, nose shape, and risks factors for illnessincluding some mental illnesses. Vulnerability to SUDs does not come from one specific gene; however, it has been identified that offspring of those with SUDs have biological (genetic) differences that place them at higher risk of developing an SUD during their lifetimes. An example of this can be found with the allele of DRD2, a dopamine receptor gene. This gene is usually identified in those who are more prone to SUD of alcohol and/or cocaine. Other SUDs related to cigarette smoking, cannabis (marijuana), and opioids also have specific genetic alleles that might play a part in the disease, and identification of that gene can indicate the possibility of increased risk. Just as there are genetic indicators for those at higher risk, there are also some individuals who have a genetic predisposition against SUDs, like the CYP2A6 protective allele, which would make a person who smokes cigarettes feel sick, thus providing a disincentive to smoke (Genetic Science Learning Center, 2013).

\section{Epigenetics}

Epigenetics refers to the "study of changes caused by external or environmental factors that alter the function of genes" (Marshall, 2017, p. 5). Just as genetics can increase or decrease a risk factor for the development of a disease, environmental factors also come into play, creating the dynamic interchanges that can result in genetic alterations. The National Institutes of Health (NIH) asserts that epigenetic regulatory systems can allow our genetic material to respond to the environment, and that these changes can then be passed onto our offspring. This change has been identified in cocaine users, whose children are more likely to have proteins that are commonly seen in those with SUD for cocaine. Research has demonstrated that the existence of these proteins shows an increase in animals to exhibit more drug-seeking behaviors (National Institute on Drug Abuse [NIDA], 2016). Why one person can be affected by a substance and another not formerally was considered individual weakness but has been demonstrated, through the discovery of this and other evidence, that SUDs reflect the extremely complicated, multidimensional impact of genes on the individual and environmental exposure on genetic development. 


\section{Experience}

We often say that mental illness does not only affect one person, it affects the family. Our families, like it or not, are our first and primary sources of learning and emotional attachment. In the United States, it is estimated that over 8 million children reside in a home with a person with an SUD (U.S. Department of Health and Human Services [DHHS], 2011). As is reflected in the BMHD, the experiences we have over a lifetime significantly affect our emotional development. Growing up in a household where a family member, especially a caregiver, has an SUD will have a negative impact on the emotional development of that child.

\section{Fast Facts in the Spotlight}

The federal Drug Enforcement Agency (DEA) expanded access to treatment for SUDs related to opioids by nurse practitioners (NPs) and PAs.

At present, 5,000 NPs and PAs have trained and have been approved to provide treatment for opioid SUD through the Comprehensive Addiction and Recovery Act (CARA). The program requires completing 24 hours of training. The 8-hour Drug Addiction Treatment Act (DATA) waiver course and the 16-hour Providers' Clinical Support System for Medication Assisted Treatment (PCSS-MAT) course can be accessed free of charge at pcssmat.org/education-training/ mat-waiver-training/.

\section{STATISTICS ON SUDS IN THE UNITED STATES}

\section{SUD Overview}

The use of illicit drugs has been increasing in the United States, with almost $10 \%$ of the American population engaging in illicit drug use, a number up from 2002. About a quarter of those surveyed indicated that some illicit drug had been taken during the preceding month, with a fifth of those indicating marijuana use (Figure 1.2). Although most other drugs being used have plateaued since 2003, the use of marijuana continues to rise, perhaps secondary to the legalization of its use in multiple states for medical and recreational use. The NIH reported, in 2013, that there were almost 20 million users over the age of 12 . The trend for the use of cocaine was decreasing, in opposition to the use of methamphetamine, which was on the rise with 
over half a million users in 2013, up from 353,000 in 2010. By 2015, 20.5 million Americans, ages 12 and over, had an SUD, 2 million of which involved prescription pain relievers and 591,000 involved using heroin (ASAM, 2016).

The age of indoctrination to drugs is in the teen years, with more than $50 \%$ of new users starting with marijuana. The age group most likely to be using is those in their late teens and early 20s, with almost one quarter of 18- to 20-year-old Americans reporting illicit drug use. The other age group that has an increasing use of illicit drugs includes those in their 50s and 60s (National Institutes of Health/ NIDA National Survey of Drug Use and Health, 2018). Overall, alcohol use by Americans under 21 is decreasing, and not surprisingly so has driving under the influence of alcohol. The number of Americans smoking cigarettes has declined from 2002, perhaps due to the rise of vaping. There has been a decline of $7.7 \%$ in the reported rates of alcohol dependence/abuse since 2002; however, alcohol dependence/abuse is still the most common reported abuse, followed by marijuana.

The good news is the stabilizing or reduction in use/abuse of multiple categories of drugs. The bad news, however, is the increase in drug overdoses from opioids, and the treatment gap for providing those with SUDs the therapies that could help them toward recovery (NIH Drug Facts, 2013). Less than $1 \%$ of those in need actually receive treatment for their SUD in a facility trained and focused on their diagnosis.

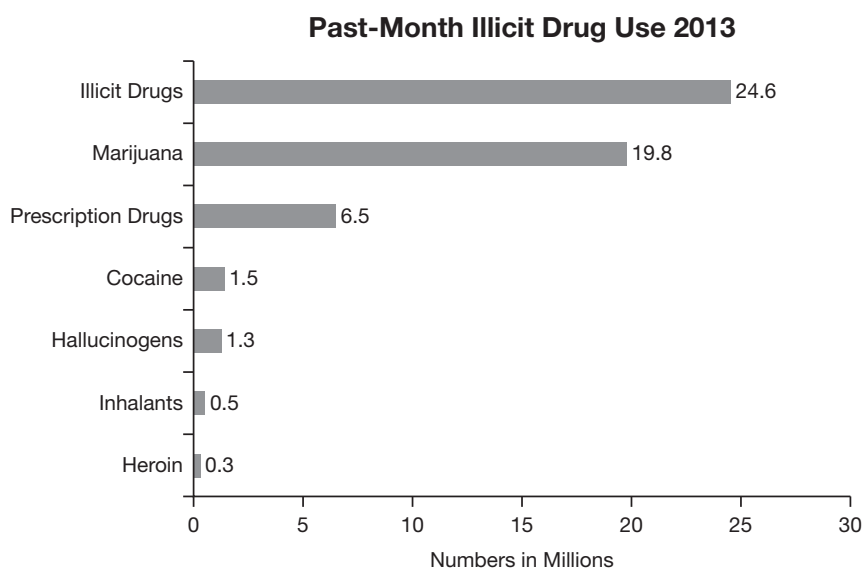

Figure 1.2 Past month illicit drug use: 2013.

Source: Park-Lee, E., Lipari, R. N., Hedden, S. L., Copello, E. A. P., \& Kroutil, L. A. (2016, September). Receipt of services for substance use and mental health issues among adults: Results from the 2015 National Survey on Drug Use and Health. NSDUH Data Review. Retrieved from https://samhsa.gov/data/ 


\section{SUD Prevalence in the Young Adult and Adult Populations}

According to the national survey of drug use and health, conducted by the NIH in 2016, divided into age group categories (>12, 12-17, $18-25$, and $>25$ years) and substances, the greatest usage indicated was alcohol use, followed by illicit drug use, cigarettes, and marijuana. Lifetime alcohol use for all those surveyed over 12 years of age was $80 \%$, with about one quarter (27\%) of those between 12 and 17 years having used alcohol, $81 \%$ between the ages of 18 and 25, and $86 \%$ over 25 years of age. These numbers are high compared to those using cigarettes, smokeless tobacco, illicit drugs, cocaine, hallucinogens, heroin, inhalants, LSD, and other nonprescribed medications. Illicit drug use was indicated by almost half those surveyed (48.5\%), with more than $56 \%$ of the 18 - to 25 -year-olds indicating recent and lifetime usage. Marijuana usages were slightly lower (44\%), with the largest group (51\%) again in the 18- to 25 -year-old range (NIH, 2016).

The NIH conducts the Monitoring the Future surveys, examining youth trends in substance use, which illustrated that, except for the use of marijuana, the use of illicit drugs by eighth, 10th, and 12th graders showed the lowest rate of increase in 20 years. The same report, however, showed a lowered perception of risk from using multiples substances including, but not limited to, LSD, cocaine, and inhalants, which could normalize the trying of substances by this group. Usage of nonprescribed pain medications (e.g., Vicodin) was reduced by $51 \%$ in the eighth graders, $67 \%$ in the 10 th graders, and $74 \%$ in the 12 th graders, stating that obtaining these medications had become more difficult. Although marijuana use remained unchanged in the 10th and 12th graders, daily use of marijuana exceeded daily cigarette use in all grades $(8,10$, and 12$)$, reflecting a declining use of cigarettes and a leveling use of marijuana (Figure 1.3). The use of alcohol in all groups also demonstrated a significant 5-year decline. Use of synthetic drugs (K2, herbal incense, synthetic marijuana) has also had a significant drop in usage since 2011. The use of heroin by adolescents ages 12 to 17 remained unchanged from 2015 to 2016 at 10\% (NIH/NIDA, 2016).

Vaping by high school students was surveyed for the first time, with the results indicating that about one quarter of 10th and 12th graders vape and slightly over $10 \%$ of eighth graders. vape. Vaping is now the third most common use of substances in high school. Only alcohol and marijuana are more common in the 10th and 12th graders, and, for the eighth graders, only alcohol is used more. Vaping can be used as the delivery source for multiple other substances. The report indicated that flavoring was the most common use of vaping; however, nicotine and marijuana were also vaped. The students did identify the harm and risk in using vaping to deliver nicotine and marijuana (Figure 1.4). 


\section{Percent of Students Reporting Any Illicit Drug Use Other than Marijuana in Past Year, by Grade}

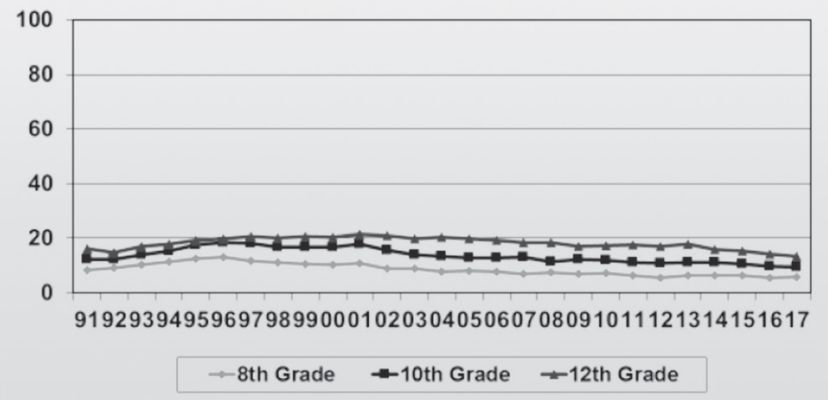

SOURCE: University of Michigan, 2017 Monitoring the Future Study

Figure 1.3 National Institutes of Health monitoring the future.

Source: National Institute on Drug Abuse; National Institutes of Health; U.S.

Department of Health and Human Services. https://www.drugabuse.gov/publications/ drugfacts/monitoring-future-survey-high-school-youth-trends

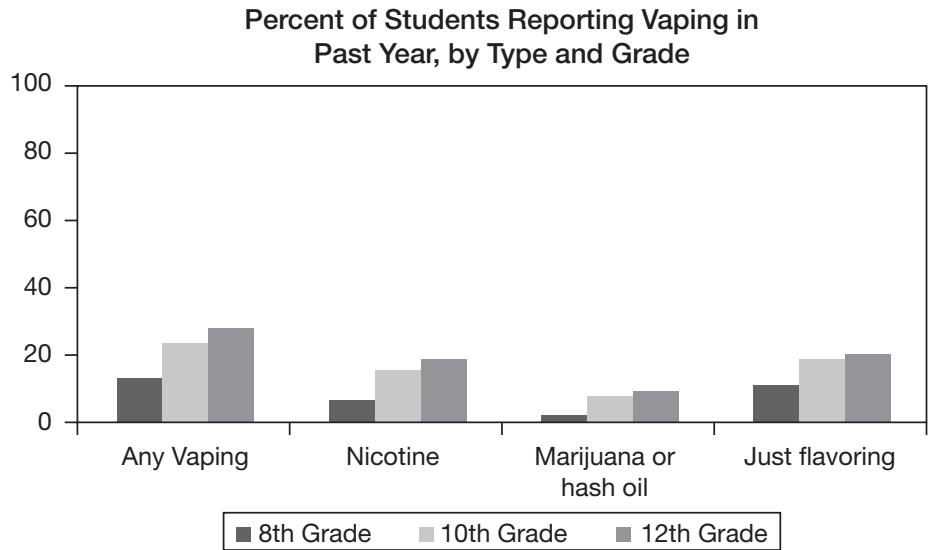

Figure 1.4 National Institutes of Health percent of students reporting vaping in 2017.

Source: University of Michigan 2017 Monitoring the Future Study 


\section{Opioid Crisis}

The leading cause of accidental death in the United States in 2015 was drug overdose, with over 20,000 of those deaths related to pain relievers and almost 13,000 related to heroin (Rudd, Seth, David, \& Scholl, 2016). The rate of overdose, from 1999 to 2008, rose significantly parallel to the increase in prescription pain relievers (American Society of Addiction Medicine [ASAM], 2016). The vast majority of those surveyed about their opioid addiction in 2014 (94\%) identified the use of heroin as the alternative to the expensive, and often hard to access, prescription pain relievers (Cicero, Ellis, Surratt, \& Kurtz, 2014). Heroin use by adolescents (12-17 years of age) was estimated to be around 21,000 in 2015, with about 6,000 diagnosed with a heroin used disorder in 2014 (Center for Behavioral Health Statistics and Quality [CBHSQ], 2016). Women are more likely to be prescribed pain relievers even though they are more susceptible to dependency than men (CDC, 2013). The increase of prescription opioids for men from 2010 to 2013 was $237 \%$. The increase for women during that same period was $400 \%$ and was accompanied by an increase of overdose deaths for women from 0.4 to 1.2 per 100,000 (Hedegaard, Chen, \& Warner, 2015; CDC, 2013).

\section{Cost to the Nation}

The annual cost of substance abuse is over $\$ 740$ billion a year. These costs, according to the NIH, include the loss of productivity, the need for subsequent healthcare, and costs related to associated crime. The reported overall costs for tobacco use is $\$ 300$ billion, alcohol $\$ 249$ billion, illicit drugs $\$ 193$ billion, and prescription opioids $\$ 78.5$ billion (NIH, 2013). These costs, however, do not take into consideration the terrible emotional cost to individuals, families, and communities who battle the SUD crisis on a daily basis.

\section{THE SAFE ENVIRONMENT}

The question of establishing a safe environment to prevent, where possible, SUDs from arising, as well as the creation of a safe environment for the identification and treatment of SUDs, is a topic that continues to grow. SUD is a mental health concern and should be treated as such. Prevention, where possible is the first goal, and early identification and treatment is the second. Youths who engage in experimentation with alcohol, tobacco, and drugs need to be able to hear clear, consistent messages from family members, school 
officials, and other role models. Adults can engage youth in discussions, demonstrate caring, provide factual information, pay attention to behaviors and attitudes, and help the youth build resistance skills in a protective and honest environment. Parents should know what resources the schools (from kindergarten to college) provide to students and their families, and what programs are available for parents to stay current and aware of their child's academic and emotional engagement. Use of substances can occur as an experimental testing or as a way to avoid peer pressure. Bullying and other aggressive behaviors can make a student feel the need to escape from reality. Youth who are known to have another mental health problem, like depression or anxiety, should be encouraged to seek professional help, avoiding self-medication.

Connecting with youth, creating a place for honest discourse and access to help, and using the resources provided by the federal government (e.g., Know Bullying app) and state, school, and local treatment centers can provide skills and strategies for parents, educators, and health professionals.

Families with an adult not yet being treated for an SUD can seek help, with the understanding that an SUD is a mental health issue and requires mental health intervention. SUD affects the whole family, increasing the likelihood of emotional disturbances in the home if help is not obtained. Families should engage in family therapy when possible and engage in a family approach to substance abuse treatment. The SAMHSA website (www.findtreatmentsamhsa.gov) can be a good resource to provide to families. Nurses can identify the resources available in a community to support the family in helpseeking behaviors.

Removing the temptation to engage in the use of substances can also help create a safe environment. Removal of known substances of abuse from an environment can assist the person in recovery, as well as the family members, to feel safer. There is a list of websites at the end of this chapter that can be used as resources for people dealing with SUDs.

\section{THE LEGAL AND ETHICAL ISSUES}

Legal issues in provision of healthcare do not change due to the patient's diagnosis. Confidentiality and privacy issues are paramount, and the Health Insurance Portability and Accountability Act (HIPAA) is clear about not sharing information on a patient except in specific instances. When we are dealing with SUDs, there is an additional concern, however, due to the impact that social stigma 
can have and how discrimination by others can hamper the road to recovery. There is a specific law, 42 U.S.C. $\$ 290 \mathrm{dd}-2$ titled "Confidentiality of Alcohol and Drug Abuse Patient Records," in the federal regulations. State laws also protect patient confidentiality, allowing the healthcare professional the privilege to refuse information without a subpoena. The set of rules that define the protection afforded to the provider is different from state to state, and an understanding of these laws is the responsibility of the healthcare provider practicing within the scope of that state and license. The instances where the confidentiality of information might be waived are when there is specific consent by the patient, if there is evidence of abuse (child or elder), and if the information is subpoenaed.

Ethics is involved in studying the concepts of right and wrong, not in a legal sense but in a moral one. Ethics has a number of principles including justice, autonomy, beneficence, nonmaleficence, and fidelity. Embedded in our ethical approach to patient care are the commitments to providing impartial and equal care to all, believing our patients have the right to make their own decisions, to do right or good by others, to do no harm to others, and to be truthful. We also have the duty to treat all patients, as well as a duty to warn others when there is a real concern for patient or provider safety. Ethical boundaries are sometimes strained when we find ourselves in a place where we have dual relationships, like learning a colleague has an SUD, or when we know that the resources that are needed cannot be accessed by our patients with limited funds.

To make sure our decisions related to provision of care to our patients, those with and without SUDs, there are a couple of steps we can put into action. First, we can examine our own beliefs and values and identify those situations in the clinical arena that might incur a problem. Determine if the issue is ethical or legal in nature. Is the problem one that is due to an emotional response, is it based on a personal past experience, or is it one that objectively requires legal advice? Consider all options-is there a support system in your institution to deal with ethics and legalities? What actions can be made, and after discussion, are you comfortable with the decisions that are being made? Creating an "ethics grand rounds" where general cases can be discussed in an ongoing forum, can help avoid the pitfall of letting personal values and principles override the principles of ethical care.

It is imperative that the nurse, and all healthcare providers, prior to treating a family or individual with an SUD, understand their own feelings about and experiences with SUDs. Ethical dilemmas often arise when we are unaware of our biases and deep-seated value judgments, which could cloud our ability to provide safe and effective care. 
Patients with SUDs can evoke situational reactions from healthcare professionals, which can lead to the delivery of care that is impacted by personal bias. Questions of morality, whether SUD is a choice, or an individual's right to autonomy can arise and cloud the situation. In order to balance the healthcare provider's personal and professional standards, there might be a time that the institutional ethicist might be needed.

\section{Fast Facts in the Spotlight-Time for Reflection}

What would you do? Why would you do it? Ms. $X$ has come to the emergency department due to a high fever and flu-like symptoms. While taking her vitals, she tells you she is on a needle exchange program, and due to her use of heroin, she is afraid that she is also HIV positive. She says she would like to get into treatment, maybe a detox program, but she is unemployed and has a young child—so making any big change is not going to work for her.

- What is the most important thing to do first?

- How do you feel about Ms. X?

- Is there something that makes you feel as though you might be judging her behaviors?

- Will you treat her differently from the patient in the third cubicle who also has complaints of signs and symptoms of influenza?

\section{ROUNDUP}

Healthcare providers are people too. We have likes, dislikes, beliefs, and attitudes. Substance use, from smoking cigarettes to using potent, dangerous pain killers, affects people in every walk of life, including healthcare workers. Providing best evidenced care to our patients with SUDs requires that each of us take an honest look at our own lives, identify where our beliefs and attitudes might interfere with our ability to provide safe, ethical, patient-centered care, and get support to learn more about this brain disease that has affected so many lives.

\section{LINKS TO LEARN MORE}

- Genetics and epigenetics of SUD: NIH and NIDA:

www.drugabuse.gov/publications/drugfacts

/genetics-epigenetics-addiction 
- Resources for families and people affected by SUD and related mental health issues: (www.findtreatment.samhsa.gov)

- Faces \& Voices of Recovery: www.facesandvoicesofrecovery.org

- The partnership at Drugfree: org www.drugfree.org

- The National Suicide Prevention Lifeline: https:// suicidepreventionlifeline.org/

- The National Alliance on Mental Illness: www.nami.org

- Mental Health America: www.mentalhealthamerica.net

- NIDA's National Drug Abuse Treatment Clinical Trials Network: drugabuse.gov/about-nida/organization/cctn/ctn

- NIDA’s DrugPubs Research Dissemination Center: drugpubs. drugabuse.gov

- The National Institute on Alcohol Abuse and Alcoholism: niaaa.nih.gov

\section{References}

American Society of Addiction Medicine (ASAM). (2016, May). Opioid addiction 2016 facts and figures. Retrieved from https://www.asam.org/ docs/default-source/advocacy/opioid-addiction-disease-facts-figures .pdf

Bronfenbrenner, U., \& Morris, P. A. (2006). The bioecological model of human development. In R. M. Lerner (Ed.), Handbook of child psychology, sixth edition-Volume 1: Theoretical models of human development (pp. 793-828). Hoboken, NJ: Wiley.

Carlson, R. G., Nahhas, R. W., Martins, S. S., \& Daniulaityte, R. (2016). Predictors of transition to heroin use among initially non-opioid dependent illicit pharmaceutical opioid users: A natural history study. Drug and Alcohol Dependence 160, 127-134. doi:10.1016/j.drugalcdep.2015.12.026

Center for Behavioral Health Statistics and Quality (CBHSQ). (2016). Key substance use and mental health indicators in the United States: Results from the 2015 National Survey on Drug Use and Health (HHS Publication No. SMA 16-4984, NSDUH Series H-51). Retrieved February 2, 2018, from http://www.samhsa.gov/data/

Center for Substance Abuse Treatment. (1998). Substance abuse among older adults. Rockville, MD: Substance Abuse and Mental Health Services Administration (US). (Treatment Improvement Protocol (TIP) Series, No. 26). Appendix A: Legal and ethical issues. Retrieved January 22 from https://www.ncbi.nlm.nih.gov/books/NBK64415/

Centers for Disease Control and Prevention. (2013). Prescription painkiller overdoses: A growing epidemic, especially among women. Atlanta, GA: Centers for Disease Control and Prevention. Retrieved February 1 from http:// www.cdc.gov/vitalsigns/prescriptionpainkilleroverdoses/index.html

Centers for Disease Control (CDC/NCHS). (2017). National vital statistics system, mortality. CDC wonder. Atlanta, GA: US Department of Health and Human Services, CDC. Retrieved from https://wonder.cdc.gov 
Cicero, T. J., Ellis, M. S., Surratt, H. L., \& Kurtz, S. P. (2014). The changing face of heroin use in the United States: A retrospective analysis of the past 50 years. JAMA Psychiatry, 71(7), 821-826.

Genetic Science Learning Center. (2013, August 30). Genes and addiction. Retrieved January 19, 2018, from http://learn.genetics.utah.edu/content/ addiction/genes/

Hedegaard, H., Chen, L. H., \& Warner, M. (2015). Drug-poisoning deaths involving heroin: United States, 2000-2013. NCHS data brief, no 190. Hyattsville, MD: National Center for Health Statistics. Retrieved January 20, from, http://www.cdc.gov/nchs/data/databriefs/db190.htm

Marshall, B. (2017). Fast facts for managing patients with a psychiatric disorder. New York, NY: Springer Publishing Co.

Mowrer, O. H. (1947). On the dual nature of learning-A reinterpretation of conditioning and problem solving. Harvard Educational Review, 17, 102-148.

Mowrer, O. H. (1951). Two-factor learning theory: Summary and comment. Psychological Review, 58, 350-354.

Mowrer, O. H. (1956). Two-factor learning theory reconsidered, with special reference to secondary reinforcement and the concept of habit. Psychological Review, 63, 114-128.

Muhuri, P. K., Gfroerer, J. C., \& Davies, M. C. (2013, August). Associations of nonmedical pain reliever use and initiation of heroin use in the United States. CBHSQ Data Review. Retrieved from https://www.samhsa.gov/data/ sites/default/files/DR006/DR006/nonmedical-pain-reliever-use-2013.htm

NAMI Comments on the APA's Draft Revision of the DSM-V Substance Use Disorders. (n.d.). National alliance on mental illness. Retrieved February 1, 2018, from http://www.namipasco.org/wp-content/uploads/2014/06/ Substance-Use-Disorder_Factsheet.pdf

National Institute on Drug Abuse (NIDA). (2016, February 1). Genetics and epigenetics of addiction. Retrieved January 23, 2018, from https://www .drugabuse.gov/publications/drugfacts/genetics-epigenetics-addiction

National Institute of Health (NIH). (2016). Retrieved January 23, 2018, from https://www.drugabuse.gov/related-topics/trends-statistics

National Institute of Heath/NIDA. (2016). Monitoring the future. Retrieved January 17, 2018, from https://www.drugabuse.gov/publications/drugfacts/ monitoring-future-survey-high-school-youth-trends

National Institutes of Health (NIH). (2013). NIDA nationwide trends. Retrieved January 17, 2018, from https:/www.drugabuse.gov/publications/ drugfacts/nationwide-trends

National Institutes of Health/NIDA National Survey of Drug Use and Health. Retrieved January 27, 2018, from https://www.drugabuse.gov/ national-survey-drug-use-health

Rudd, R. A., Seth, P., David, F., \& Scholl, L. (2016). Increases in drug and opioid-involved overdose deaths United States, 2010-2015. Morbidity and Mortality Weekly Report, 65, 1445-1452. doi:10.15585/mmwr.mm655051e1 Substance Abuse and Mental Health Services Administration (SAMHSA). (2015). Substance use disorders. Retrieved December 10, 2017, from https://www.samhsa.gov/disorders/substance-use 
U.S. Department of Health and Human Services (DHHS). (2011). Administration on children, youth, and families. Child maltreatment. Washington, DC: U.S. Government Printing Office. Retrieved January 23, 2018, https://www.acf.hhs.gov/sites/default/files/cb/cm11.pdf

Vowles, K. E., McEntee, M. L., Julnes, P. S., Frohe, T., Ney, J. P., \& van der Goes, D. N. (2015). Rates of opioid misuse, abuse, and addiction in chronic pain: A systematic review and data synthesis. Pain, 156(4), 569576. doi:10.1097/01.j.pain.0000460357.0199 